\title{
Editorial
}

\section{Brands without borders?}

The Internet has proven to be more, much more, than the Citizen's Band Radio (CB) of the 1990s. Since the United States government created it in the 1940s, it languished as a quaint communication method for academics and the military. Ever since 1989, when the United States government finally ruled that it was legal to do commerce on the Internet, its growth has been exponential. Now, ten years later, we are being forced to cope with the changes that the Internet is bringing to trade marks and to brand management.

The effect that the Internet has and will continue to have on brand management and the development of trade marks is profound. One of the fundamental principles that needs to be grasped to understand the power of the web is reflected in these four words: Geography doesn't matter.

The readers of this journal will immediately understand how that fundamental Internet principle collides, sometimes violently, with an equally fundamental principle of brand management, namely: Brand management is geography dependent.

How many trade-mark agreement and branding strategies revolve around clear and very specific articulation of territory? The answer is almost as many as exist. The emphasis on geography is often found in the paragraph of the trade mark licence that directly follows or is included in the granting clause.

Trade marks are the oldest form of consumer protection. As such, trade marks and brands require, and are defined by, consumers with very specific demographics in cultures and contexts that have location and territory.
The territory of a brand used to be a tangible place, locatable on a map. The territory of a brand now, however, is increasingly not easily mapped. Take, as example, the territory of the brand for a game played around the world: 'Scrabble' word game. The mark has two owners: Mattel and Hasbro, and for many years the two owners had a straightforward marketing strategy. Hasbro took the United States and Mattel took the remainder of the world. But then came the Internet. Who would own the much coveted domain address of Scrabble.com? How would each company identify the source of the consumer in terms of the divided territory which each was obliged to serve, protect and sell to?

One answer can be found by looking on the web where you will find what many individuals herald as the first and best 'gateway' site. The consumer enters a page with a map of the world and is invited to identify his or her location. That self-selection triggers the trade-mark owner's second page or the link to which the consumer will be directed.

But what of those individuals who are perambulating, or those who have several domiciles? What of a woman lawyer who practises in California, but also spends two months a year at a house in Wales? Whose consumer is she? The Scrabble solution has no solution to this dilemma. And what effect does this have on the consumer's sense of brand? We are living in times that resemble the old Chinese curse: 'may you live in interesting times'.

Intellectual Property law is devoted to protecting intangible assets which are, or used to be, made manifest to the consumer in the form of some physical manifestation. The 
unparalleled worldwide growth of the Internet means that the paradigm is changing from goods and services that are provided to the public in some configuration with an atom structure, to goods and services that are ordered and often delivered in an electronic, soon to be photonic, structure.

In the atomic structure, I hold a book, or a pen or a cold drink in my hand and I think about transferring it to some other person. My thoughts in that instance usually address a paradigm of scarcity. Specifically, if I give that other someone that pen or cold drink that means that I will be deprived of physical ownership of that item composed of atoms. This is an 'either/or' analysis. If I give the pen, I will no longer have the pen.

In the electronic and photonic structure, I have information or text on the hard disk of my computer and I think about transferring it to someone else. In the thinking of giving that which is resident on the hard drive of my computer, my thoughts do not address a paradigm of scarcity, but to a paradigm of abundance. That which is on my hard drive will still be there after I hit the send button, regardless of the number of people I send it to. If I give the content, I still have the content.

This paradigm shift changes the perceived value of that which is being transferred. In the abundance paradigm, the good or service has a different, often reduced, value to that in the scarcity paradigm.

Also, the simultaneous, almost parallel nature of the Internet's effect on commerce was especially apparent this spring, when the United States Supreme Court ruled in the L'Anza $v$ Quality King case that manufacturers could not use copyright to halt the reimportation of shampoo bottles bearing copyrighted labels through US customs. That case revolved around the movement of goods composed of atoms crossing traditional country borders.

Within the very same season, the United States was forced to concede that it was no longer capable of managing exclusively the assignment of Internet domain names worldwide. One of the stated reasons for this concession was that it was impossible to govern the Internet using conventional concepts of borders and ports. Moreover, the courts throughout the world are increasingly full of cases percolating through trial and appeal levels which are dedicated to Internet disputes. These disputes begin with the very threshold question of where should the dispute be heard? For instance, let's take that peregrinating woman lawyer.

She is flying on a plane from New York to London and is delighted to find that there is a computer and an Internet port from her seat. She logs onto the Internet and to a site that allows her to place a bet on the World Cup Soccer match in France. Unknown to her, the server for that site is in Bermuda and is owned by Germans. It is illegal to place such bets in her home state of California but legal in Wales. She then logs into an adult web site. The adult web site is physically located on a server in Moldova and is owned by a Singapore company. The woman finds some material which is particularly insulting and harmful to one of her clients, so she makes a copy of some of the content and sends it to her hard drive for action later. Where can she file the law suit on behalf of that client?

The examples are endless and usually even more complex than that recited above. Imagine how much more complex brand management will become as the locus of 'where' becomes 'everywhere'.

The Internet creates spatial paradoxes that are impacting our static perceptions of trade marks and brand. It is no longer possible to say with confidence what is inside and what is outside of a brand's territory. The very concept that a brand's consumers occupy a particular identifiable space is subject to challenge on the Internet.

As we move into this globalised economy, the notion of 'loss' has been identified as a 
dominant feeling experienced by consumers. This experience includes a loss of orientation. The Internet's lack of place is an example of this loss of orientation.

But this is also the strength of the brand because the brand, the trade mark, serves, in the best instance, as a vehicle for the consumer's trust. Trade marks and brands which are functioning properly fulfil trust expectations. This trust and reliance on trade marks and brands can help heal the sense of loss.

Trade marks and brands are going to be integral to the paradoxical interaction of place and time that we are experiencing both globally and locally. Brand loyalty can shape a new relationship with the consumer in the global economy.
In recent issues of this journal, a number of issues related to brand and trade-mark valuation have been ably addressed. As the Internet evolves and our ability to integrate the new paradigms that the Internet brings to commerce and brands increases, we will need to find new measurements of valuing the brand, the trade mark. As geographical territory and the historical sense of borders increasingly do not matter, we begin to wonder what the new metaphorical 'continents' will be. Perhaps time zones are the last continents that will govern where branded activity and goods can be managed.

\section{Katherine Spelman} Editorial Board 